2017-02-01

\title{
A sense of the cycling environment: Felt experiences of infrastructure and atmospheres
}

\author{
Simpson, Paul
}

http://hdl.handle.net/10026.1/5491

\subsection{7/0308518X16669510}

Environment and Planning $A$

SAGE Publications

All content in PEARL is protected by copyright law. Author manuscripts are made available in accordance with publisher policies. Please cite only the published version using the details provided on the item record or document. In the absence of an open licence (e.g. Creative Commons), permissions for further reuse of content should be sought from the publisher or author. 


\section{A sense of the cycling environment: felt experiences of infrastructure and atmospheres}

[Forthcoming in Environment and Planning A]

This is an accepted manuscript of an article published by Sage in Environment and Planning A on 28th September 2016 (early online) available at: doi: 10.1177/0308518X16669510

Paul Simpson

School of Geography, Earth and Environmental Sciences

Plymouth University

paul.simpson@plymouth.ac.uk

\section{Acknowledgments}

An RGS-IBG Small Grant funded this research. Thanks go to the cyclists who participated in the research, Nicky Harmer for assisting with data analysis, Justin Spinney for commenting on an earlier draft, Jon Shaw for conversations about transport policy, and Jamie Quinn for producing Figure 6. The paper has benefited greatly from the engagement of Deborah Dixon and the three anonymous referees. 


\title{
A sense of the cycling environment: felt experiences of infrastructure and atmospheres
}

\begin{abstract}
This paper explores how cyclists gain a sense of the environments they move through by considering their felt experiences of the affective atmospheres that emerge in and through their movements. More specifically, the focus falls upon how various forms of transport infrastructure choreograph bodies in their movements through the city and so contributes towards the co-production of various affective atmospheres between differently mobile bodies. Drawing on video-interviews with 24 commuter cyclists in Plymouth, UK, the roles that such infrastructures and atmospheres play in shaping the experience of cycling through shared forms of transport space are considered. Based on this, the paper argues that such felt experiences of affective atmospheres should be considered further in planning for cycling and when evaluating future developments.
\end{abstract}

Key words: Affect, Atmosphere, Cycling, Infrastructure, Mobility.

\section{Introduction}

Recently cycling has received increasing levels of interest amongst a range of social scientists, transport scholars, urban planners, and policy practitioners. Cycling's potential significance to the promotion of health and wellbeing, reducing carbon emissions, and easing road congestion has resulted in concern over how cycling participation can be increased (Horton et al 2007). Investment has been made in countries with low rates of cycling participation in the provision of cycle-specific infrastructure and cycling proficiency training (Aldred 2012). Following such efforts a range of work has been undertaken, largely in quantitative terms, to evaluate the efficacy of the measures they have adopted (see Parkin et al 2007, Pucher et al 2010). Equally though, recent research has added to this by trying to understand the experience of cycling (Horton et al 2007). The ways in which specific meanings, imaginaries, and significance come to be bound up with cyclists and their practices has figured strongly here (Skinner and Rosen 2007). For example, Aldred (2010; 2012; 
2013) has explored the complex ways in which cycling identities and participation are connected with forms of citizenship, governance, and social stigma. Furthermore, Spinney (2006) discusses the embodied experience of cycling and the diverse meanings of places and landscapes that are generated by cyclists in their technologically mediated movements. However, there is still more to be done in unpacking the complexity of such cycling experiences and how these may be important factors to consider when trying to evaluate cycling initiatives and infrastructure (Horton 2007; Spinney 2009; van Duppen and Spierings 2013).

Developing such work on infrastructure and cycling experiences, this paper will explore the ways in which cyclists gain a sense ${ }^{1}$ of the environments they move through by considering their felt experiences of the affective atmospheres that emerge in and through their movements. This is an area of cycling that has received limited attention (Spinney 2009; Cupples and Ridley 2008). Notably, Jones (2005; 2012) has outlined some of the near over-whelming affects that can be felt in 'risking life and limb' in traversing the city by bike. Developing this, this paper will focus on how more mundane affects and shared experiences come to be felt between and by cyclists. Despite the apparently banal nature of the majority of the moments on the move discussed here fleeting gestures, passing comments, momentary encounters, and so on - a wide range of affects are felt in their unfolding. Such banality belies a subtle and shifting field of 'minor' affective atmospheres and experiences through which a sense of the cycling environment emerges (Anderson and Ash 2015).

In such day-to-day experiences of cycling different forms of infrastructure play a part in generating a sense of the cycling environment as infrastructure acts to choreograph the

\footnotetext{
${ }^{1}$ In talking of a 'sense of the environment' here sense is being taken to refer to a general legibility of experience, to the fact that the world in some pre-reflexive way often 'makes sense' to us (Nancy 1997). Such a sense of the environment is produced through practice. It is not, however, something that will necessarily cross the threshold into the realm of reflexive consciousness or meaning generation, though it does provide the grounds and medium for such a crossing and generation to happen.
} 
interactions that occur between differently mobile bodies, objects, and materialities. Infrastructure enacts a "relational process of 'infrastructuring' by which infrastructured spaces, subjects and practices emerge" (Merriman 2016: 84). This plays a significant part in the production of specific, and at times shared, affective atmospheres in the urban environment that infect how those environments are perceived, felt, and come to be experienced. Therefore, this paper will examine how felt experiences of cycling emerge amid movements across various infrastructural and planned interventions that encourage certain interactions with other mobile bodies and materialities, which in turn inflects the feel of these spaces given the atmospheres that come to find consistency amid these compositions of bodies and materialities.

The next section outlines the paper's understanding of the way cycling experiences come to be 'co-produced' in relations between cyclists, motorists, pedestrians, transport infrastructure, and the various affective atmospheres they all contribute to and find themselves within. Section 3 further elaborates on the understandings of infrastructure, materiality, and atmosphere that underpin this. Section 4 outlines the empirical research that informs the discussion. Section 5 reflects on the affective atmospheres that emerge from and come to be felt in cycling amid various cycle infrastructures, socialities, and materialities. The conclusion suggests that such felt experiences should be considered further in planning for cycling and outlines ways that this could be explored.

\section{Co-producing mobile experiences}

This paper seeks to understand how experiences of cycling are 'co-produced' between mobile bodies, subjectivities, objects, practices, materialities, atmospheres, and infrastructures (Merriman 2014). It has been argued that movement in a lot of transport research "is overwhelmingly utilitarian in nature and consequently there is an enormous expanse of lived experience that such an approach fails to make visible" (Spinney 2009: 819). Such work arguably overemphasizes the significance of transport infrastructure, which "leads to a neglect of affective and embodied dimensions of cycling" (Cupples 
and Ridley 2008: 259). However, there has in turn been a tendency in mobilities research to pay insufficient attention to "the infrastructures, technologies, materialities, and spaces that are integral to the embodied movements of human subjects" (Merriman 2014: 177). Therefore, it is important that research on the experiences and meanings accrued by cyclists in their movements does not forget the highly planned and regulated environments that those movements and experiences often happen within (Shaw and Hess 2010). The aim here then is to respond to Merriman's call for a form of 'symmetrical study', one that focuses on mobile experiences and 'trace[s] the social relations, materialities and practices" that the use of transport infrastructure brings about (2014: 177).

However, to this binary between mobile practices and socio-material infrastructure a third point, or rather volume, of reference begins to emerge. What about the atmospheres that cyclists co-produce in their movements, in their interactions with their environment, and in their encounters with other variously mobile bodies? What implications do they have for mobile experiences and the perception of transport environments?

Recent scholarship has begun to think through the significance of affective atmospheres to the unfolding of social life. Such atmospheres relate to a generally felt "quality of environmental immersion that registers in and through sensing bodies while also remaining diffuse, in the air, ethereal" (McCormack 2008: 413). These atmospheres become manifest in "shifts in the (in)corporealities of embodiment that we retrospectively identify as feelings and emotions" (Anderson 2005: 647). These atmospheres come to be apprehended by an emergent subject in a given encounter and, in turn, are potentially named or qualified in light of that perception. But equally, in being moods which are 'in the air' (Bohme 2016), such atmospheres come to be enrolled in the apprehensions of other bodies. Therefore, atmospheres present means for thinking through how affects are felt collectively, are transmitted and felt 
within/between such collectives, and so shape various bodies' capacities to affect and be affected (Anderson 2014).

While shared and collectively felt, atmospheres also remain ambiguous, indeterminate, and irreducible. The specific compositions of bodies present in a given context, their disposition and demeanor, and so their capacities to affect and be affected, will change over time as practices unfold. This means that the same atmosphere might be registered differently by different bodies depending on their specific embodied socialcultural-political histories and capacities (Ahmed 2010). Equally, this also means that different atmospheres might co-exist or rub up against each other in the same space (Anderson and Ash 2015). In the context of this paper, cyclists (and other mobiles bodies) will each have a sense of the environments they move through from such encounters which are mediated through (but not necessarily determined by) such embodied capacities/dispositions/histories. At times a common sense might be felt collectively in a similar way between a range of mobile bodies. At other times, bodies may feel such atmospheres differently, or an entirely different atmosphere altogether.

This irreducibility of atmospheres re-implicates the sorts of infrastructures, materialities, and socialities that mobile bodies enter into in their movements. The specific combinations of cyclists, motorists, pedestrians, and a range of non-human materialities that come together to produce both momentary and enduring affective atmospheres are, to varying degrees, channeled ${ }^{2}$ by transport infrastructures. Therefore, this paper will think through the ways in which atmospheres come to matter and be felt in and for cyclists through the interaction of variously disposed and equipped bodies, transport systems and infrastructure, discourses, norms, personal and social histories, micro- and macro-scale materialities, and so on. Before doing so, it is important to reflect in more

\footnotetext{
${ }^{2}$ Rather than talk of a 'disciplining' of the affective experiences of cyclists (Jones P 2012), the emphasis here is on the co-involvement of various human and non-human agencies that play a part in the unfolding of affective experiences, which includes some degree of organization or choreographing.
} 
detail on the role that infrastructure can play in organizing such affective atmospheres and felt relations.

\section{Infrastructure, experience and atmospheres}

Cycling infrastructure has been considered in a variety of ways. For example, work has explored the rational decisions that underlie mode and route choice and sought to make recommendations for policy intervention based on this (Menghini et al 2010). Equally, research has sought to predict the impact of various measures - for example, increasing time spent on off-road cycle paths or segregated on-road cycle lanes - on cycling participation (Pucher et al 2010; Parkin et al 2007). Furthermore, the practicing of infrastructure itself has been considered in terms of the implications of social institutions and technical infrastructures for how people practice mobility (Aldred and Jungnickel 2014). This can be seen, for example, in declining participation in cycling and its displacement in relation to emerging systems of automobility (Aldred 2012). Here we can see a sensitivity to the open-ended nature of practices and their entanglement with various forms of situation and context, and so an understanding normproduction/reiteration/change.

This latter approach to thinking about cycling infrastructure resonates with a range of recent developments in the study of infrastructure more generally. This has sought to re-think a variety of infrastructures beyond dictionary-based understandings where infrastructure is simply "the basic physical and organizational structures (e.g. buildings, roads, or power supplies) needed for a society or enterprise to function" (OED). Instead, infrastructure is understood as something that is practiced, imagined, and social-cultural (Angelo and Hentschel 2015). In this sense, infrastructures are seen to "drive and maintain standardization, reflect and embody historical concentrations of power and control, and are instruments through which access is managed" (Dourish and Bell 2007: 416). Therefore, infrastructure has agency and is seen to have a bearing on the 
unfolding of social life (Amin 2012). Through its design, construction, and repeated (mis)use within a specific social-cultural-political setting it holds capacities to affect (and to be affected by) mobile practices and experiences.

Such affective capacities become tied up with the experience of infrastructure in that "the embedding of a range of infrastructures into everyday space shapes our experience of that space and provides a framework through which our encounters with space take on meaning" (Dourish and Bell 2007: 417). Or as Amin (2012: 68) notes, "Urban form itself generates distinctive public feelings". Infrastructures can be understood as "architectures of circulation" that "broker interactions - between people, between things, between people and things - and shape a larger environment that supports, secures and segments these interactions" (Tonkiss 2015: 384-385). Something as banal as a car park, for example, is "not static and stilled...rather they are complex environments which gather and resonate with multiple affects and atmospheres, 'infrastructuring' subjects, environments and communities in diverse ways" (Merriman 2016: 95). These infrastructure-mediated interactions can be more or less convivial, more or less constraining-enabling, in terms of how these interactions unfold and these affect circulate (Amin 2012).

Thinking through the practicing of cycling infrastructure in terms of felt experiences in/of cycling, some suggestive work has been undertaken. Spinney (2006) shows the importance of cycling technology - gears, pedals, shoes, etc. - to the sensory experience of cycling and the hybrid cycling subject that is enacted in this. It seems appropriate, then, to ask how other technological interventions such as transport infrastructure shape experiences of cycling and so to explore the "processes whereby affective life is mediated and capacities to affect and be affected are organized" (Anderson 2014: 16). While not necessarily thought of in terms of "objects which inform and shape movements" as a gear or pedal might (Spinney 2006: 715), roads, paths, barriers, and other forms of infrastructure can have similarly significant implications in 
the mediation and organization of how affects are felt by cyclists, between cyclists, and in relations with other urban inhabitants.

Based on this, a fundamental point to consider when thinking in terms of affective atmospheres is that atmospheres too are not just neutral backdrops. Rather, they are in the first instance "a force field in which people find themselves" (Stewart 2011: 452). This forcefulness may be designed or directed to varying degrees (Bohme 2016). Through the design of a space and its particular layout/configuration, different sorts of atmospheres might be produced, encouraged, and felt. It is possible that atmospheres can be manipulated or 'engineered' by design interventions and technologies (McCormack 2008), such as those that might occur through the installation of various forms of transport infrastructure. This might not necessarily be the agenda of such design or the terms in which such design would be evaluated; affects here are not necessarily the specific 'object-targets' here (Anderson 2014). While we might consider a feeling of safety a form of atmosphere, their evaluation is more likely to relate to the implications of such design for actual safety. Also, it is not necessarily the case that a specific affective outcome or form of relation will be designed into a space through any such intervention as it is by no means straightforward to 'make' a particular atmosphere that will be felt in a certain way (Bohme 2016). However, such design practices do come to play a significant part in the production of 'circumstantial' atmospheres that various mobile bodies feel in the way that they set the conditions for particular configurations of bodies and materialities to move along different trajectories and at different speeds (McCormack 2014).

\section{Researching Cycling Experiences}

The research discussed here was undertaken in Plymouth, UK. Plymouth presents an interesting setting for thinking about the experience of cycling and cycling infrastructure. In some ways Plymouth is quite suitable for cycling. The city is relatively compact, with an area of approximately 30 square miles and a maximum distance from the city center 
to its furthest outskirts of 7 miles (Plymouth City Development Company, undated). Many of Plymouth's key destinations are within reasonable cycling distance from a range of residential sub-districts. There are, though, some significant obstacles to cycling. Plymouth's climate is on average wetter than the rest of England and the city, on a north-south axis at least, is quite hilly. Further, part of the motivation for conducting this research in Plymouth came from the city's relatively low participant rates (roughly in line with the national average) (Plymouth City Council 2011) and relatively marginal situation when it comes to cycling investment. Plymouth was not, for example, part of the recent English cycling city/towns initiatives meaning that there has not been the same level of investment as in other nearby locations which have seen significant increases in cycle journeys (for example, Exeter, previously a 'Cycling Town', or Bristol, previously 'Cycling City'). Despite this, in recent years Plymouth City Council has been actively involved in the assessment and development of the City's cycling infrastructure, primarily through the adoption of a 'Strategic Cycle Network' plan. This has produced a city plan detailing a network of routes, cycle paths, and cycle lanes targeted at both experienced and less experienced cyclists that the Council has created and/or aims to create to encourage cycling and improve safety. Such plans are specifically focused on addressing recognized issues with Plymouth's cycle infrastructure, including its often fragmented nature, and to ensure that key routes into the city are provided in a joinedup, direct, and more pleasant manner (Plymouth City Council 2011).

The research itself involved 24 commuter cyclists ( 13 males $/ 11$ females) of varying age, experience, and approach to cycling. ${ }^{3}$ These cyclists were recruited through a range of gatekeeper organizations, including: Bike User Groups from Plymouth University, Plymouth City Council, and the Marine Biological Association; the Plymouth Cycle Campaign; personal contacts; and subsequent snowballing. Most participants were

\footnotetext{
${ }^{3}$ A senior transport planner at Plymouth City Council and the head of Plymouth Cycle Campaign were also interviewed, specifically focusing on plans, developments, and issues with Plymouth's cycling provision/infrastructure.
} 
aged in their 30 s and 40 s (roughly $75 \%$ of participants) and the remainder evenly split between their 20s, 50s, and 60s. Participants commuted by bike at least 2-3 times a week while also driving and/or using public transport. A small number also cycled competitively in bike races/triathlons and most cycled recreationally. All participants had cycled in Plymouth for at least 2 years, most had experience of commuter cycling in other cities, and most grew up cycling in the UK.

Despite this relative continuity, these cyclists demonstrated a range of approaches and dispositions toward cycling. Some could be described as confident cyclists - for example, being comfortable cycling on the road/amid traffic - while others were more cautious - generally sticking to cycle paths/pavements. At the same time, but not necessarily with absolute correspondence, some cycled at relatively high speed and chose their route on the basis of directness and continuous movement, while others were happy to 'pootle along' more slowly (both on and off the road). There were also divergent opinions and experiences within such apparent groupings. A significant consideration in this research emerges from the diversity in these cyclists' past experiences, embodied sensibilities, practical skills, and perspectives as this potentially had implications for their abilities to act or susceptibilities to be affected. The specific 'angle of arrival' of each cyclist into their encounters with the infrastructure discussed in the specific context of a given journey (Ahmed 2010), came to mediate (though not necessarily determine) such cyclists' specific experiences of the collective atmospheres that emerged amid/through their movements (Anderson 2014).

The research entailed a video-interview approach where the cyclists were provided with a head-cam and asked to cycle their usual commuting route (Simpson 2014). Each cyclist produced 40-60 minutes of video. This ranged from a single hour-long journey to several 10-15 minute journeys. These journeys took in routes between a range of residential areas (Plymstock, Elburton, Hooe, Peverell, Mannamead, Compton, Stoke, and Mutley), as well as nearby towns/villages to the East and West (Torpoint, Ivybridge, 
and Exeter [including a train journey]), and prominent employers in the city (Plymouth University and Plymouth City Council's offices in the city center, The University of St Marks and St John's and Derriford Hospital to the North, Devonport Dockyard to the West, and the Marine Biological Association to the South). The author reviewed these videos and a bespoke set of interview questions was developed for each participant. Interviews lasted approximately 1 hour and involved participant and interviewer watching and discussing a selection from the participant's head-cam video. In addition to being asked questions, participants were also given the chance to volunteer comments about the video/their experiences.

This method was selected in an attempt to address the challenge of researching something as banal, and very often 'background', as infrastructure and the felt experience of atmospheres. As is often noted, infrastructural systems tend to be "taken for granted" and are "only revealed when they collapse or fail" (Graham 2001: 340). Similarly, cyclists tended to want to talk about the more spectacular events or issues, and so affects, that happened in their cycling than the more mundane experiences that they had on a day-to-day basis. It was not necessarily the case, though, that the video 'captured' the affects or felt relations experienced by these cyclists. These are often not easily seen. However, the video material was useful as it facilitated reflection upon aspects of the experience of undertaking these movements that might have been passed by if not for the detailed record of events the video generated (Simpson 2014). As such, video was employed "as a way of retaining and evoking some of the context and detail of the practices under scrutiny whilst allowing the researcher to talk through [such] practices 'as they happen' during playback with participants" (Spinney 2011: 166). The video provided a useful starting point from which a discussion of these cyclists' everyday felt experiences of various infrastructures and atmospheres could take place. Examples of events recorded in those videoed journeys that spurred such feelings/discussion are included at various points below. 


\section{Felt experiences of infrastructure and affective atmospheres}

Like much of the UK, provisions for cycling in Plymouth are a product of the limited visibility of cycling within post-World War 2 urban redevelopment and the growing emphasis on providing for motoring (Aldred 2012). During World War 2 Plymouth's city center was badly bombed. Through the post-war rebuilding, specific provision for cycling was limited. Redevelopment was based around the production of a central shopping district that now forms something of an island around which traffic circulates. In turn, many central residential areas were relatively un-affected by the wartime bombing meaning that their relatively narrow Victorian and Edwardian era streets remain. The legacy of this is that Plymouth's cycling infrastructure is very piecemeal, being based around a combination of (generally short) on-road cycle lanes, shared lanes with buses/taxis/motorbikes, stretches of combined cyclist-pedestrian footpath, and advanced start lanes at traffic lights. Amongst this cyclists tend to inhabit that grey middle ground between pedestrian and motorists depending on the specific route being travelled (Spinney 2008).

This transport infrastructure tends to bring together differently mobile bodies, bodies moving at differing degrees of speed and slowness, moving along differing trajectories. This leads to various atmospheres finding consistency between these mobile bodies. For example, interactions with various forms of motor vehicle are clearly significant in generating certain affective atmospheres for cyclists through the way their relations are coordinated by road infrastructure, the degree to which this is observed, amongst a range of other factors. Such roads are "charged composition[s]' of 'bodies, rhythms, orientations, and atmospheres'" (Stewart 2014 cited in Merriman 2016: 86). The cyclists in this study discussed a range of experiences of being amongst traffic. For some, motorists in Plymouth generally acted 'okay' and a relatively convivial atmosphere emerged for them - enough space was given when passing, people treated each other with appropriate standing, and so on. Others reported motorists acting dangerously (or 
even aggressively) in the lack of space afforded to cyclists (Figure 1), and noted that certain infrastructure only acted to exacerbate this. Traffic calming islands were commonly criticized given how they produced 'pinch points' that often resulted in unwelcome proximity for these cyclists. Specific disconcerting atmospheres tended to coalesce around such infrastructure and the relations they tended to stage. For others again, it wasn't even the specific actions of motorists or the implications of road infrastructure that mattered here, it was just that being in proximity to traffic presented a highly disconcerting circumstance.

Figure 1: Proximity Affects

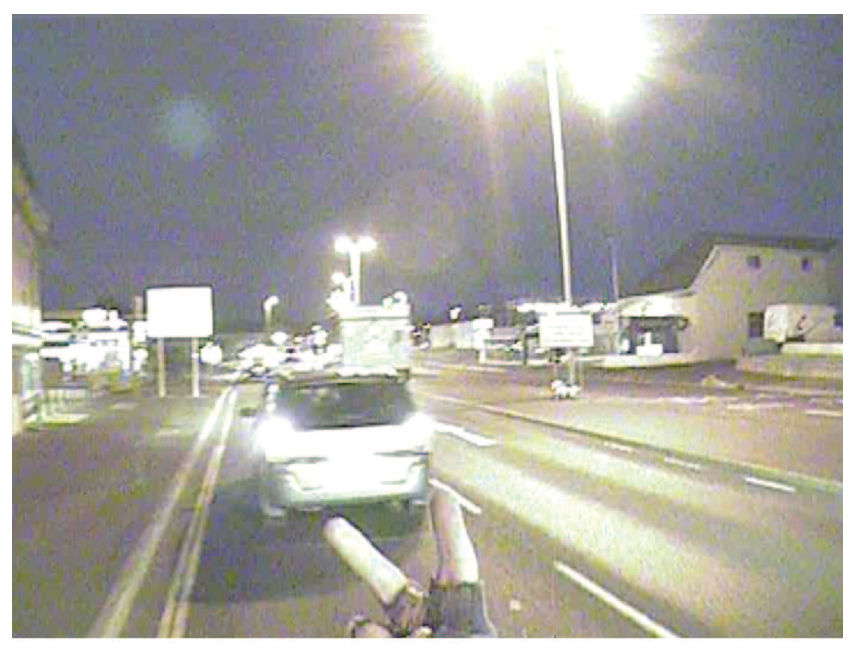

The car in the image has just passed very close to the cyclist when overtaking. The affect that this proximity produced is manifest in the cyclist's gesture towards the motorist.

It was, though, the use of infrastructure that entailed sharing spaces with pedestrians that really stood out from the interview discussions in terms of cyclists' felt experiences of affective atmospheres. This section will, therefore, focus on the interrelations of cyclists, infrastructure, and pedestrians in such shared environments. 


\section{1) Sharing spaces with pedestrians}

Shared space transport planning emerged in Europe in the late- $20^{\text {th }}$ Century as a key transport planning agenda and practice. Shared space planning entails the removal of symbolic and material demarcations between pedestrian and traffic areas. This "places emphasis on 'informal protocols and negotiation', re-introducing the challenges and unpredictable movements of mixed traffic which existed for centuries before the introduction of traffic segregation technologies in cities" (Merriman 2016: 91-92). For its advocates "Shared space may represent an important step towards widening the opportunities for communities and individuals to shape and influence the built environment in ways that encourage diversity, distinctiveness, urban quality and civility" (Hamilton-Baillie 2008: 162). It has also been suggested, though, that the evidence base for such claims is not clearly established - it is just presented as 'commonsense' and that the primacy of the car amid such planning remains unchallenged (Imrie 2012). The cycling infrastructure in question here is not entirely 'shared' in the sense that divisions still remain from motorized traffic. However, as will become clear, a range of similar principles and issues appear to apply.

There is a clear logic underlying the installation of shared cyclist-pedestrian spaces. It is relatively cheap, it allows for the provision of cycle-specific infrastructure where space is limited, and it does not disrupt existing road networks. Additionally, traffic-free routes are felt to be useful in encouraging people to take up cycling and gain experience/confidence (Jones T 2012). This is a specific focus of Plymouth's Strategic Cycle Network in its distinction between fast on-road routes for experienced cyclists and slower off-road routes for less experienced cyclists. However, such shared off-road routes can generate feelings of frustration for some cyclists who don't want to give way each time they reach a junction or to have to negotiate through groups of slow-moving pedestrians. Cyclists were keen to avoid "going up and down curbs and a sort of slightly convoluted route" (Interviewee 23: Male, 30). Even when they did use these routes they noted feelings of frustration coalescing around, for example, the staggered barriers that 
intend to stop pedestrians and cyclists junctions quickly and having "to stop, curl round, get back onto the pavement and so on." (Interviewee 1: Male, 63).

As might be expected, moving cyclists who do want to use such facilities onto what have previously been pedestrian-only spaces produces a range of collective feelings amongst both pedestrians and those cyclists. ${ }^{4}$ This sets the scene for a variety of dispositions towards cyclists to emerge. In this study, much of this did not necessarily conform to the agendas behind the planning of these spaces or the outcomes hoped for (i.e. the emergence of informal social protocols or actively considered negotiation between those using the space). These atmospheres were in turn registered/felt in the moving bodies of cyclists in a range of ways.

While shared space ideals suggest that differently mobile bodies will come to negotiate their interactions with others and that more sociable forms of transport space will come about, this assumes that all participants have (or assume) equal standing in the space. One point that emerged here was that cyclists would be viewed negatively and a confrontational atmosphere would emerge between pedestrians and such cyclists on the simple basis of the cyclists being present in these spaces. As one participant noted (Figure 2):

"although there is a sign there which says that it is [a shared lane], but you do get that don't you, where pedestrians feel that you shouldn't be on the pavement, they might sort of glare at you" (Interviewee 3: Female, 37).

\footnotetext{
${ }^{4}$ This paper focuses on the cyclists' experiences of such situations and not the ways such atmospheres and infrastructures affect pedestrians (or motorists). It is also, then, based on the cyclists' assumptions about the acts of others, and the feelings that produced, rather than a pursuit of the 'actual' intentions of those acts. Questions around such varied perspectives on infrastructure and atmospheres will be returned to in the conclusion.
} 
Figure 2: Hostile Glance
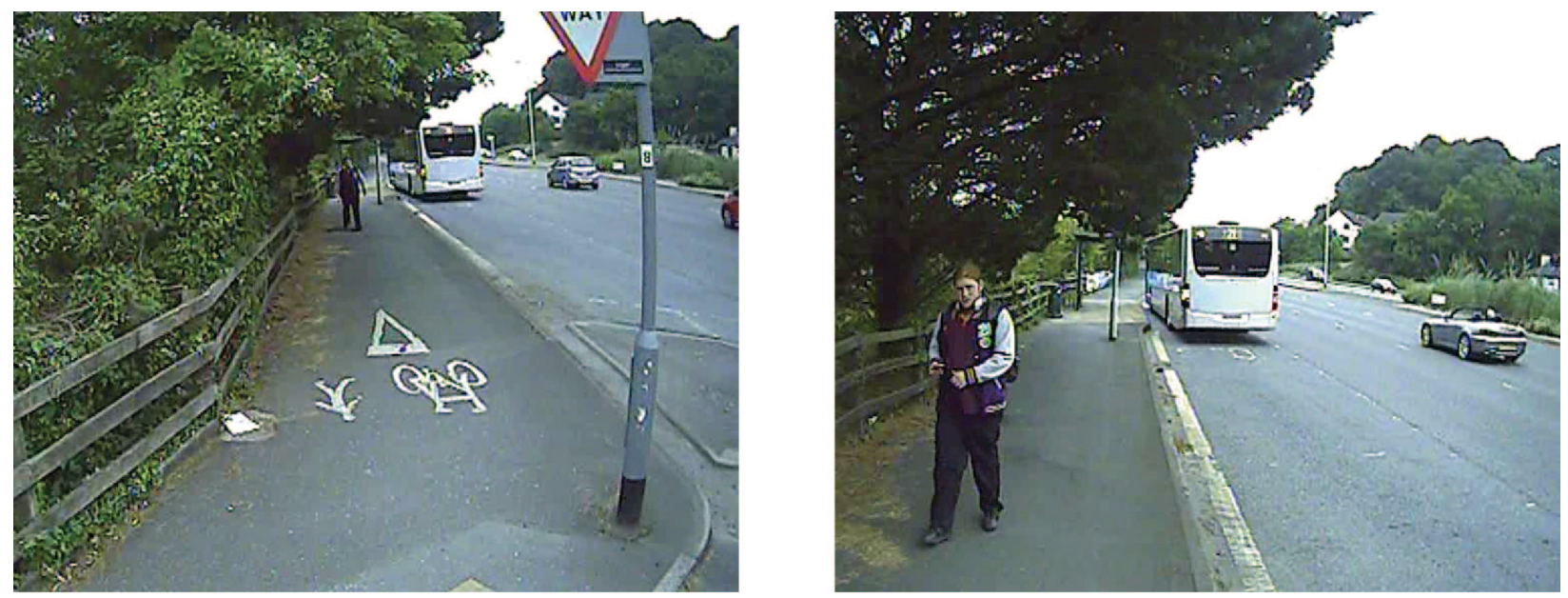

In the image on the left the cyclist approaches a shared pedestrian / cycle path. The pedestrian ahead has just disembarked from the bus at the side of the road. As the cyclist approaches the pedestrian (image on the right), the pedestrian looks up and makes an inaudible comment. In the interview the cyclist commented that it sounded like the comment included a reference to 'cycling on the pavement'.

While overt acts of aggression were very rare, certain forms of uncongenial atmospheres did emerge (Bissell 2010). It was more the subtle acts of malcontent, such as a pointed look, a shake of the head, that acted to bring about a fleeting sense of unease, of judgment, or of distance that filled the space between such cyclist and pedestrian. This proved frustrating to the cyclists interviewed given that they were technically doing nothing wrong.

In addition to using combined pedestrian-cycle lanes, many of the less confident cyclists included here also cycled on pedestrian-only pavements. This was generally done when the cyclists felt that cycling on a (non-shared) pavement was a safe thing to do. Again, though, uncongenial atmospheres were highlighted as emerging from this. As one participant commented, following being 'told off' by a pedestrian,

“I just didn't really know what to say because she was at one end of the pavement, I was at the other, we were not getting in each other's way. And it's when that happens I kind of have a problem with because...if you're just telling me off out of principle you know I can appreciate that but I'm not going to dignify that with a response...If I'm actually knocking over your 3 year old kid, sure by all means arrest 
me. But just to have a go at me for the sake at having a go at me, l'll just completely ignore it" (Interviewee 20: Female, 28).

Generally, the decision to use spaces shared with pedestrians - either where formally allowed or not - was explained in quite pragmatic terms. For example, in situations where cycling on the road would mean being amongst high-speed or heavy traffic, many of the less confident cyclists commented that such a situation would be disturbing; the combination of noise, air turbulence, and feeling exposed gave that space an intimidating atmosphere. Equally, if there was a particularly awkward maneuver a cyclists would have to make when taking a particular route (such as moving across several lanes of traffic or turning right at a very busy multi-lane roundabout), again many explained that they would use the pavement to avoid the feelings of vulnerability such situations would bring about for them.

In deciding to cycle on pedestrian only footpaths, it was generally clear that these cyclists wanted to avoid conflict. This did involve various forms of "negotiation 'in motion' with other traffic" (van Duppen and Spierings 2013: 242). While some did bemoan how 'oblivious' pedestrians could be, largely given cycling's relatively low profile in the city, many did comment that they needed to show respect towards pedestrians. Such attempts to encourage a convivial atmosphere between cyclists and pedestrians came through in a number of ways. For example, and echoing some of the shared space principles, this desire often translated into the slower speed participants cycled at when taking to the pavement (Figure 3). Equally, while pedestrians did not always positively view their presence on the pavement, some participants deliberately acted in an overtly friendly way towards pedestrians in negotiating their interactions with them. This aimed to disperse any tense atmospheres as they moved along a shared pavement. As one participant commented:

"Yeah I think sometimes people look a bit annoyed, but I smile at them and wave [interviewee pulls as silly face and waves]. And I give way to them, you know. I don't sort of ring my bell and mow them down." (Interviewee 3: Female, 37). 


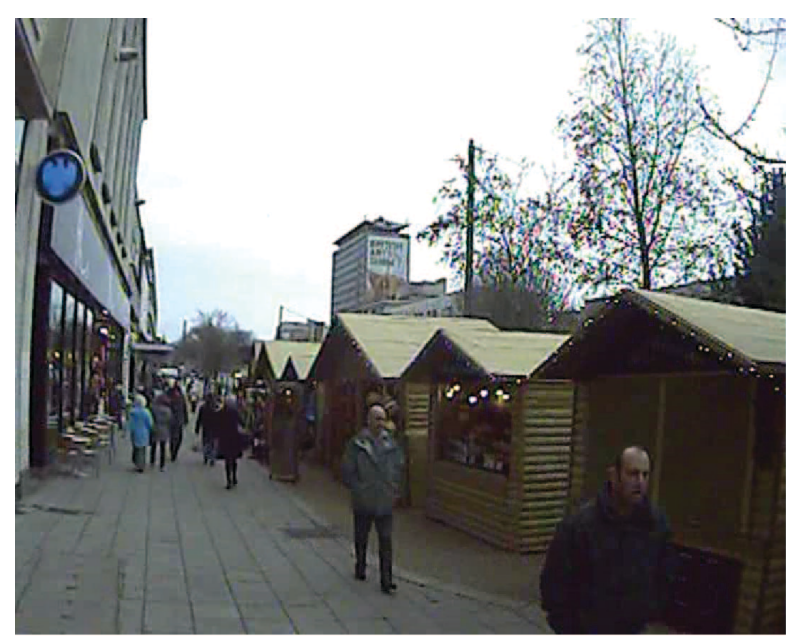

a) The cyclist is cycling down Armada Way. This is a pedestrianized area of the city but is included in the City's Strategic Cycle Network as an 'indicative route'. No markings to suggest cyclists are present appear in the area.

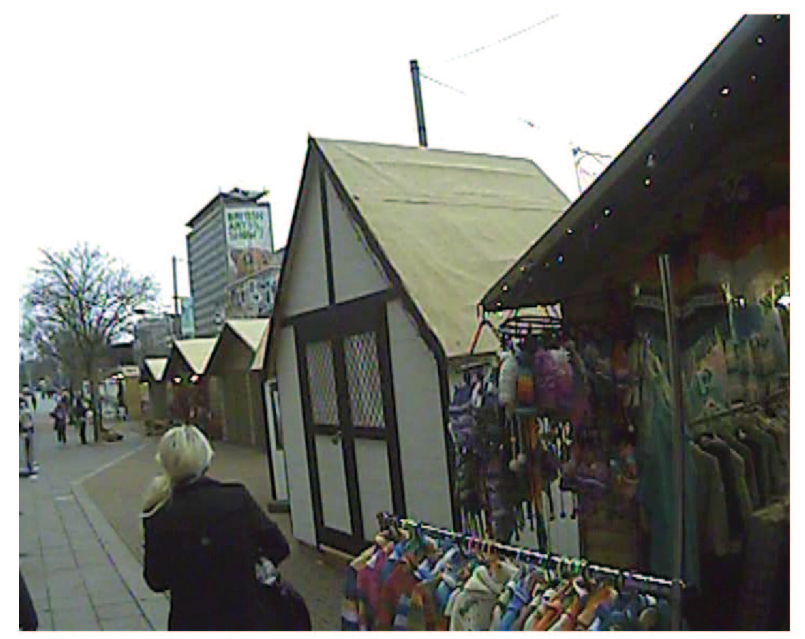

c) The cyclist slows significantly and follows behind the pedestrians who do not register the cyclist's presence despite the squeak of the bicycle's breaks.

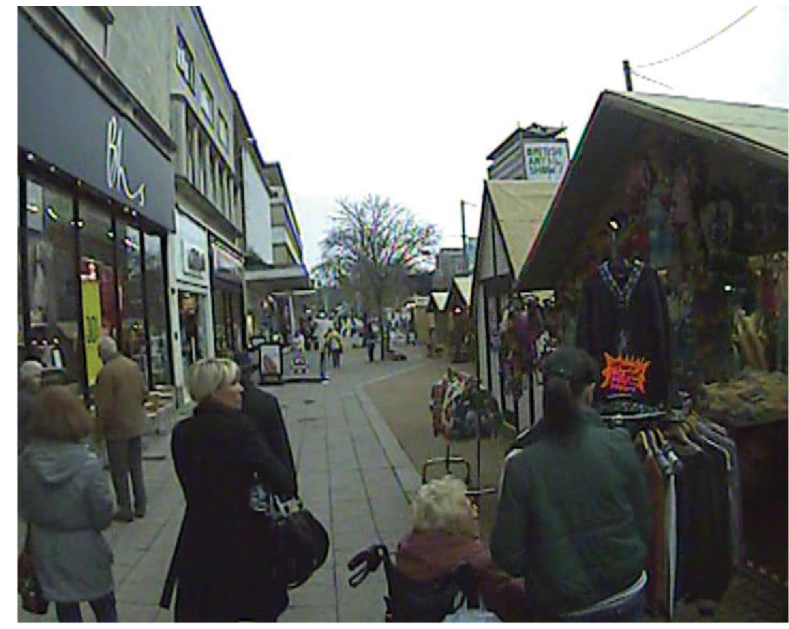

b) The cyclist approaches a group of pedestrians, some stationary looking at the Christmas market stalls, others walking slowly.

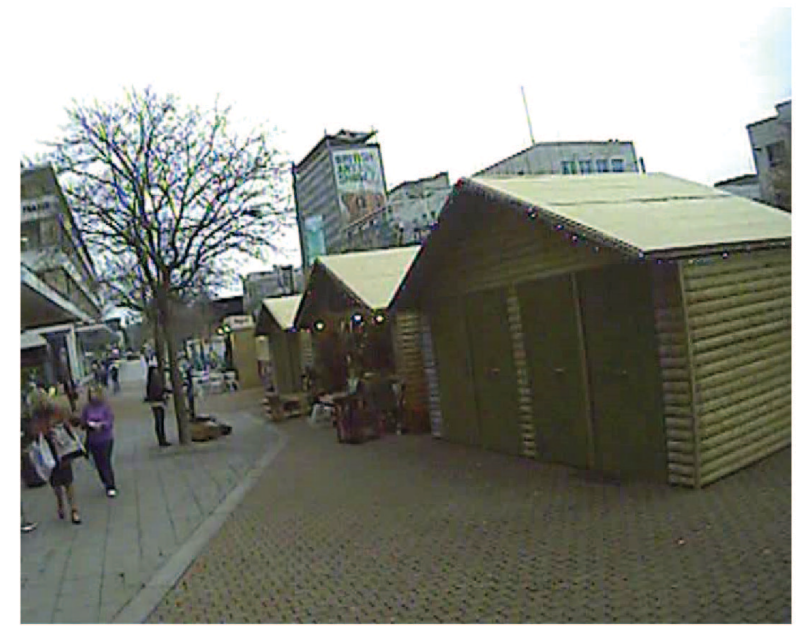

d) When space appears the cyclist gradually accelerates and moves towards less congested areas of the space.

The mention of using a bell raised an interesting point of tension here amongst the cyclists interviewed. A number commented on the problems that might emerge in using a bell when travelling through a shared space (Brown 2012). While some were 'heckled' by pedestrians for passing them from behind without ringing one, others were reticent to 
use a bell given the relatively intrusive nature of its tone. It was felt that its tone seemed too demanding or too much like a 'warning' when approaching a pedestrian:

"if I'm coming up behind someone, because of the road noise they often aren't aware of it, so l'll often choose to say 'Excuse me' when I'm quite close, rather than ring my bell...Because l've always found as a pedestrian when someone rings the bell it makes you jump. Which I suppose is what it should do, but I think it's just a bit more polite to just say 'Excuse me'.” (Interviewee 21: Male, 46) (Figures 4 \& 5).

In this sense, the bell can be seen to act as what Jane Bennett calls an operator, something that "by virtue of its particular location in an assemblage ... makes a difference, makes things happen, becomes the decisive force catalyzing an event" (2010: 9). The event brought about is a 'jump' from fright or a feeling of annoyance at the potential intrusion that the bell brings about. This, in turn, can undo the convivial atmospheres that the bell's use actually intended to produce in appearing to assert 'get out of my way'.

Figure 4: Passing with Bell
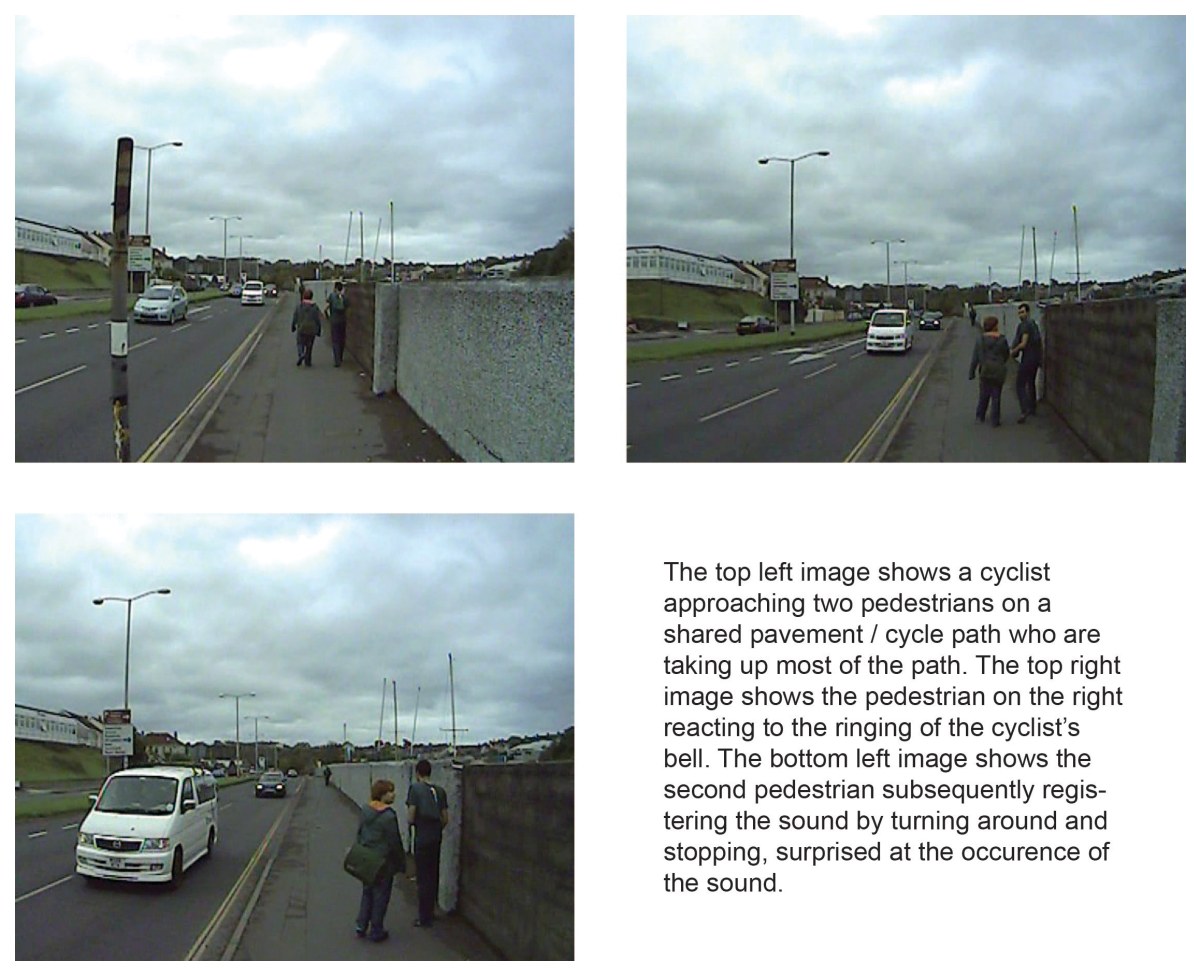

The top left image shows a cyclist approaching two pedestrians on a shared pavement / cycle path who are taking up most of the path. The top right image shows the pedestrian on the right reacting to the ringing of the cyclist's bell. The bottom left image shows the second pedestrian subsequently registering the sound by turning around and stopping, surprised at the occurence of the sound. 
Figure 5: Passing with Comment
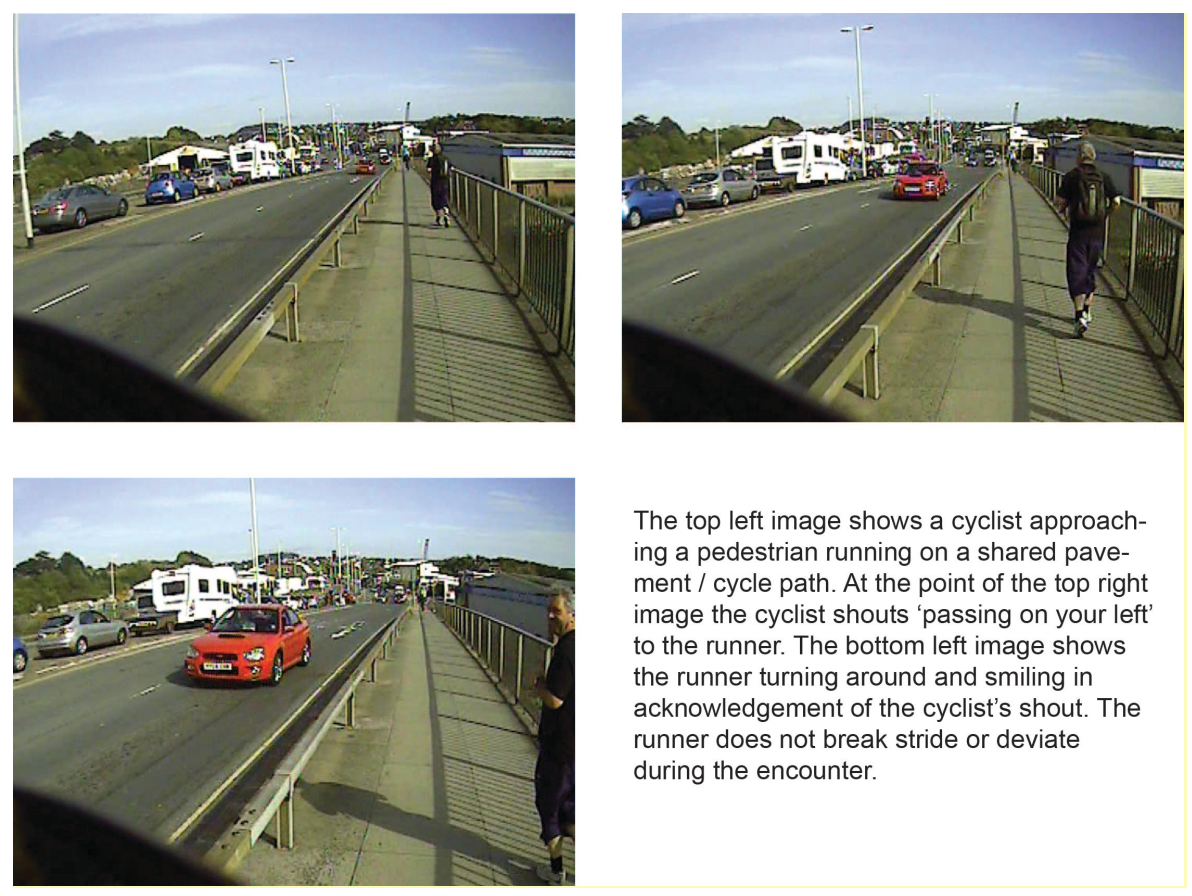

The top left image shows a cyclist approaching a pedestrian running on a shared pavement / cycle path. At the point of the top right image the cyclist shouts 'passing on your left' to the runner. The bottom left image shows the runner turning around and smiling in acknowledgement of the cyclist's shout. The runner does not break stride or deviate during the encounter.

Such challenges in finding appropriate means of interacting with pedestrians meant that many of the cyclists using shared spaces noted that they found themselves adopting a heightened sense of anticipation when around pedestrians. This does tie into some of the key claims around the positive outcomes of shared space design, specifically in terms of the "remarkable range of anticipatory and communication skills" (HamiltonBallie 2008: 171) their occupants are claimed to develop. However, here it was not the case that all mobile bodies developed such skills of anticipation. Rather, it was felt by these cyclists that the burden fell almost exclusively to them. Given their assumptions that pedestrians did not expect to encounter cyclists in Plymouth, these cyclists felt the need to become 'attuned to' and so preempt how pedestrians may react or potentially get in their way (Brown 2012), and so to engage in precautionary acts in advance of such outcomes taking place (Anderson 2010). This heightened concern and awareness then meant that many commented that they had become 'good at anticipating' through their regular cycling practices and encountering different events through this, that they would "sort of get a feeling" for what pedestrians and motorists were going to do (Interviewee 7: Male, 34). It was a case of working through a process of "'oh, there's a 
pedestrian on that side, l'll stick to this side' and 'oh, there's a pedestrian on the other side, I'll go round them'" (Interviewee 5: Male, 35), though without actually thinking through that process of negotiation quite so consciously.

This need to anticipate was heightened by the presence of some feelings of ambiguity both between cyclists and pedestrians, and amongst cyclists themselves, as to what they should actually do in these spaces in terms of passing each other. As one participant noted:

"I don't like shared cycle pedestrian areas...there are like symbols on the ground, but it's not clear...they haven't like marked one side or the other, it's just like you're supposed to use it together. And I just...I think that's really counterproductive, because even though it says at some point that it's a shared area, you're going to get people cycling and you're going to get people walking, and so you're going to get a weaving sense. Whereas if you have two areas so it's like right, you're in...if someone's walking in a cycle area then they're in the wrong, where if someone's cycling...you know whereas at the moment it's...you get people that are going to be weaved round." (Interviewee 23: Male, 30).

Without formalised guidance being evident for how to share the space (Brown 2012), or clearly established cultural norms/expectations around such encounters (which may not yet be in place given the recent introduction of these shared spaces), or a clear definition of cyclists and/or pedestrian territories in terms of signage or pavement markings, many of the cyclists here found themselves needing to weave between groups of pedestrians in these spaces. Again 'mutual consideration' was not necessarily felt to be present in these interactions. This meant that a number of cyclists felt more anxious around pedestrians than being around cars given their unpredictable actions, especially if they wanted to move at speed. On roads there were deemed to be potentially fewer permutations of what a motorist might do (even if they could have more catastrophic outcomes). Again, a transport culture based around automobility, and most participants being both cyclists and motorists, appears to have shaped the disposition, 
and so capacities to affect/be affected, of some of the participants here in terms of their proposed (or implied) solutions to the challenges such negotiations present. At the same time, in segregated transport spaces cyclists already inhabit a grey middle ground between pedestrians and motorists (Spinney 2008). Moving to shared forms of space, while arguably doing little to displace the car in transport planning priorities (Imrie 2012), appears to do little in the context of Plymouth in placing cyclists more clearly amongst other modes of mobility within the city. While generally appearing safer in the sense of there being a reduced risk of being involved in a serious traffic accident, a number of the cyclists included in this study nonetheless felt anxious in these shared spaces meaning that they came to hold unpleasant or disconcerting atmospheres.

\section{2) Separating cyclists and pedestrians}

In Plymouth notable engineering solutions to the navigation of some pubic spaces actively work against sociable interactions between cyclists and other (Aldred 2010), engineering a micro-scale form of 'boundary work' (Jensen 2013). While there was a desire for clear guidance from many of the participants in terms of who should be in what space, it was also clear that this could be over-engineered. The distinction seems to fall along the lines of color coded lanes or otherwise signaled separations between pedestrian and cyclist spaces being positive and more ridged separations not. Spaces that were formally shared out rather than solely through negotiation were desired. The complete separation of pedestrians and cyclists here, though, is broadly orientated towards mitigating the potential risk assumed in allowing pedestrians and cyclists to interact freely. This illustrates the popularity of segregated transport planning that emerged in the UK during the 1960s where it was thought that "Potential conflict and friction between different activities could be designed-out" (Hamilton-Ballie 2008: 166). However, the principles underlying such segregation-based responses to the challenge of allowing various transportation modes to move through the same space are often not based on solutions that were arrived at from 'on-the-ground' and so do not actually work 
for cyclists or for pedestrians. This is visible in the presence of bridges, railings, and other hard-engineering solutions throughout the city.

The most commonly discussed manifestation of these ideals and issues relates to a number of underpasses installed around Plymouth to allow cyclists and pedestrians to navigate across busy roundabouts. Notable amongst these is the underpass at North Cross Roundabout given its situation as a key entry point into the city center (Figure 6). ${ }^{5}$ This is a busy pedestrian junction as it forms the start of a key axis line installed during Plymouth's post-war regeneration that connects the main Train Station (to the North) with the city center and the coastline (to the South).

Figure 6: North Cross Roundabout

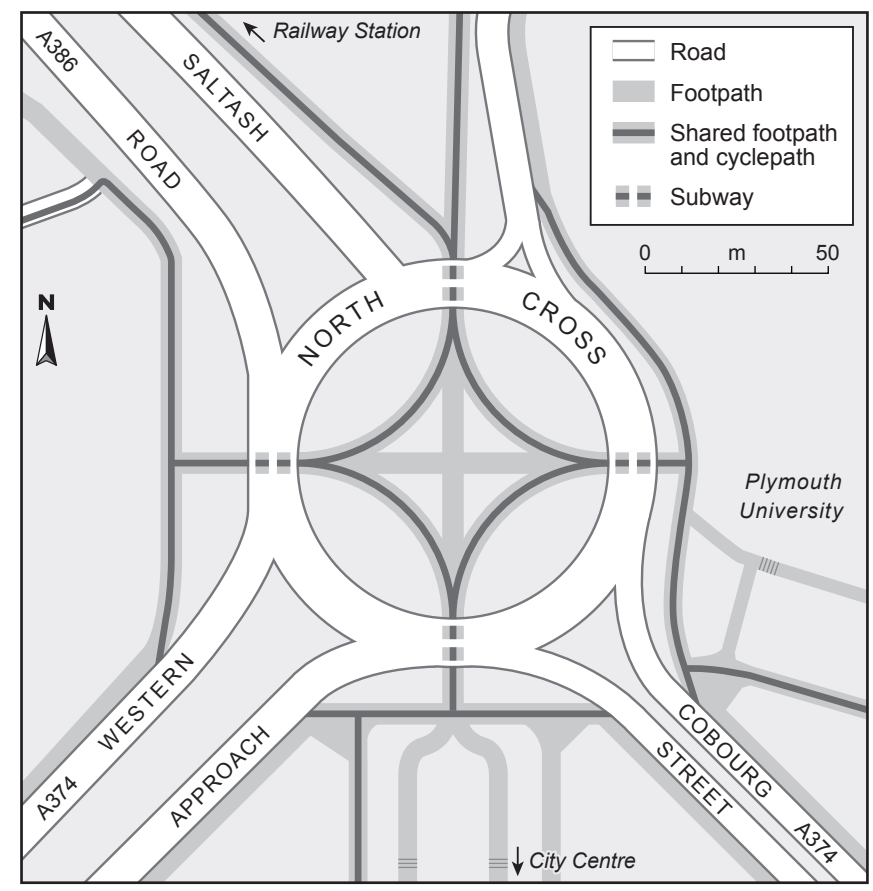

\footnotetext{
${ }^{5}$ Five of the cyclists in this study rode through this space during their filmed journeys. In addition, several others commented on it based on their recent (generally negative) experiences of cycling through it during the more open parts of the interview process.
} 
In this space pedestrians and cyclists are kept almost exclusively apart. Through a series of 'spatial prescriptions' movements through this space are, in theory at least, standardized (Spinney 2008). 'Appropriate' routes for pedestrians and cyclists are laid out both through painted markings on the ground and by metal fencing. Pedestrians are given priority in the directness of route, the space afforded to them, and in terms of who is to give way to whom. If followed, this intends to produce harmonious relations within the space by engineering risk out of the space (Figure 7).

Figure 7: Traversing North Cross Underpass

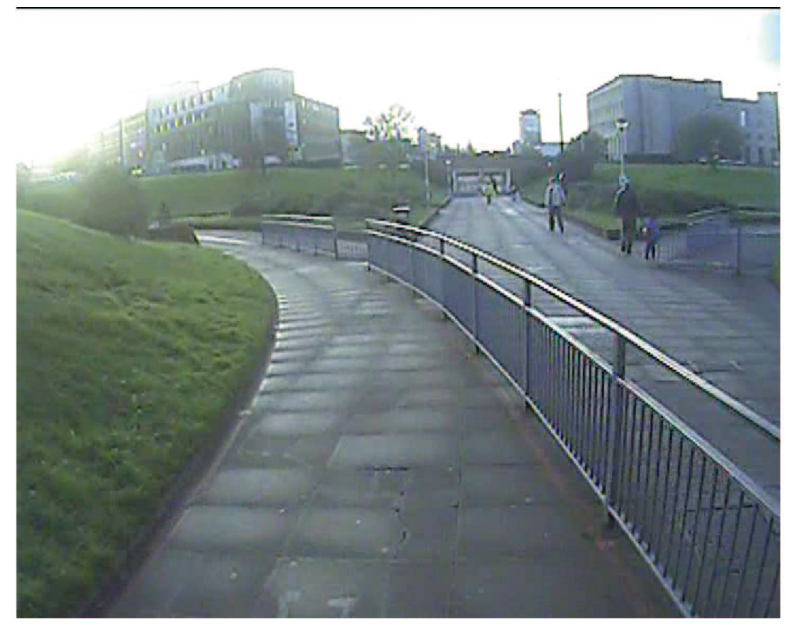

a) The cyclist entering North Cross Underpass intends to travel straight on in this image

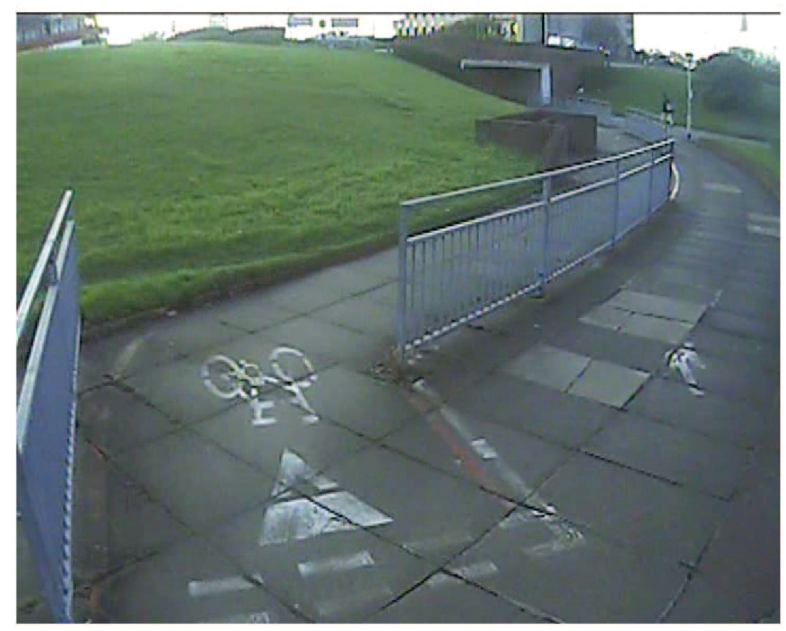

c) Traversing the space requires the cyclist to navigate through a range of sharp turns between the barriers

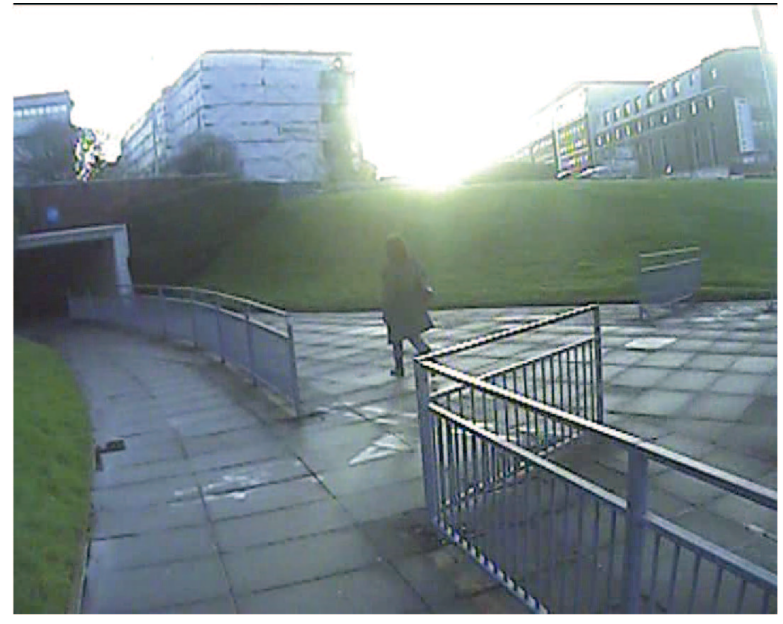

b) The barriers mean that the cyclist has to travel around the outside of the space and give way to pedestrians

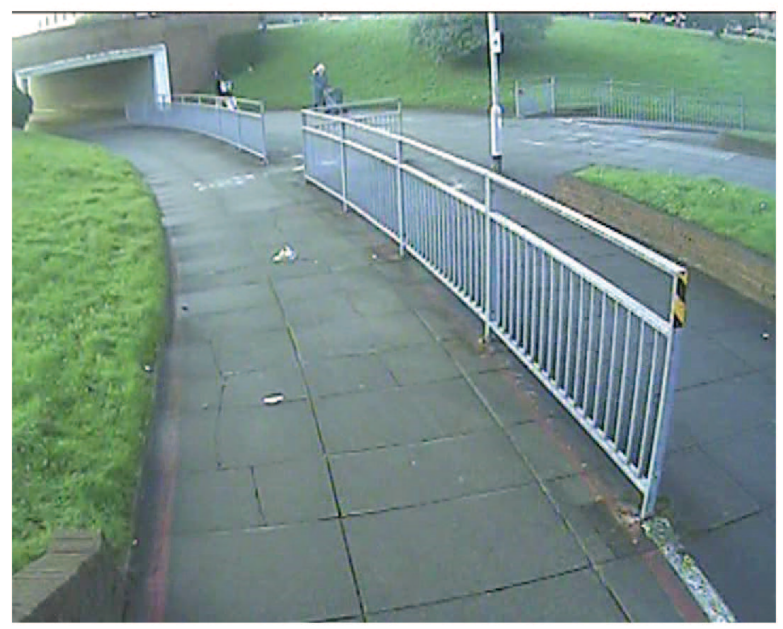

d) The cyclist curves back around the outside edge to approach their desired exit 
However, this clear differentiation of cyclists from pedestrians raises tensions. As one participant explained:

"I think what I'm quite surprised about with that roundabout is how adamant they are at separating the paths. Like it's not they [pedestrians] go straight down the middle, we [cyclists] go straight down the middle next to them, it's...'they' being pedestrians go straight down the middle... and the cyclists go around the [perimeter] avoiding the barriers, with the stops, with the give-way signs....and I don't understand why it has to be that separated...I'm a firm believer in the fact that the more you get used to bicycles being around pedestrians, the less it becomes a problem...and through that infrastructure completely separating one way of the other in that particular spot, you [cyclists] are almost made the problem...It's kind of like 'Us pedestrians can go straight, but you're going all the way round because like we will not mix with you' but it's wide enough for both" (Interviewee 20: Female, 28).

This illustrates a range of key points in terms of the sort of unintentional atmospheres such infrastructural arrangement can encourage, and particularly a confrontational 'us and them' situation (Vreugdenhil and Williams 2013). While engineering out the possibility for any kind of direct or uncoordinated encounter between cyclists and pedestrians, it seeds conditions for the emergence of antagonism between these two clearly identified groups in spatially segregating them. This can produce and propagate certain unintended confrontational atmospheres between pedestrians and cyclists through its design.

In reality, the enactment of movement through this space rarely conforms to these prescriptions. As one participant noted:

"They try to make the cyclists go really slow, but the thing is the cyclists don't want to go really slow so everyone ignores it. So this is all well meant, but that's not how things work... Unless I get in people's way I take the smoothest route... [In the video watched] I'm evidently on the pedestrian part, but that doesn't hinder anyone." (Interviewee 19: Female, 35). 
The main issue here was that this space was "designed by someone who isn't a cyclist" (Interviewee 20: Female, 28). The expectation for sharp right-angled turns resulted in a need to stop and re-start and the give-ways at the bottom of hills meant cyclists lost all momentum they had from dropping into and/or for ascending out of the underpass (Nixon 2012). Also, at the northern entrance, cyclists and pedestrians have to swap sides based on the way that the shared cycle lane/pavement is divided on the approach to the underpass. This actively encourages points of congested overlap or confusion as to where people should be and so a focal point where tensions can emerge.

Those who did broadly follow the prescriptions also noted, with some frustration, that pedestrians too did not follow the route designated for them, something again tied to a general lack of expectation to see lots of cyclists in the city:

"if you took most of the people particularly around North Cross roundabout, most of the people....walk across all the cycle lane stuff, you just plonk them straight into a similar situation in Holland, you know, they would soon get the message I think." (Interviewee 5: Male, 35).

It would appear that this set up falls foul of most of the criticisms of traffic-free routes highlighted by Parkin et al (2007). There is potential conflict with pedestrians in the division of this space between cyclists and pedestrians, there is a lack of continuity in the cycling route given the way cyclists must 'give way', the street furniture (particularly the barriers) present a significant obstacle to traversing the space, and those same barrier produce an inconvenient route. Rather than promoting a safe navigation of the space the barriers distract cyclists from the presence of others, required awkward maneuvers to be made, slowed cyclists down, and lengthened their journey. They also gave cause for arguments to start given cyclists often wanted to avoid the space designated for them for those reasons or as pedestrians too ended up in the 'wrong' space. It sets up a social distance between cyclists and pedestrian in their enforced segregation rather than allowing such interactions to be negotiated (perhaps with some 
illustration or guidance). It is evident that such "materials have the capacity to reconfigure the affective relations between" those moving through these spaces, at times in undesirable ways (Bissell 2010: 280).

Since the completion of these interviews the barriers have been removed, though some faded paint markings showing these routes and priorities remain. There is now a somewhat ambiguous situation whereby the standing of these markings is not clear. The lane markings are by and large ignored with cyclists and pedestrians sharing the overall space and making more informal navigations through it. This often involves a range of intertwined and overlapping trajectories cutting across the space. This more active and contextualized negotiation between those on the move does seem to have emerged and gives the space a more harmonious atmosphere. This is, though, perhaps tied to the traces of past infrastructuring and with that the space's history of including cyclists within it, something largely lacking from the other shared spaces discussed earlier. It is clear here then how "affects emerge from specific material arrangements that may be composed of all manner of bits and pieces" (Anderson 2014: 13). In this space, particular compositions of objects, materialities, and technologies - bicycles, bodies, paint, paving, symbols, rules, and fencing - come together to shape the ways in which both cyclists and pedestrians interact and so experience movement through this space.

\section{Conclusion}

This paper has sought to advance understandings of how cyclists gain a sense of the environments they move through by focusing on the affective atmospheres that emerge and are felt in the embodied experience of cycling. This has been pursued through an examination of the practices of commuter cyclists and their use of cycling infrastructure. The paper has explored how various forms of transport infrastructure - cycle paths, shared cycle lanes, and more general road systems - choreograph bodies in their movements through the city and produce particular forms of sociality, and so affective 
atmospheres, between differently mobile bodies. The perception and experience of such atmospheres were a product of specific momentary combinations of bodies and materialities, but also were implicated with and mediated through the corporeal and social histories that such bodies brought to bear on such encounters; both the embodied dispositions of the cyclists that have developed some consistency through their past experiences and present capacities to act, but also in light of the specific context of the UK's past and present transport systems, practices, and cultures. From this, the presence of (a lack of) feelings of conviviality between cyclists and other mobile bodies in such spaces was a key concern for these cyclists that inflected their experience of infrastructure and with that their sense of the environments they moved through.

It is important to note that such themes are now emerging also within recent UK policy discourse on cycle planning. For example, the Department for Transport's (2016) Cycling and Walking Investment Strategy highlights delivering 'better streets' that are 'civilized places' as a key ambition. In that, shared spaces that are attractive and 'function well' are suggested as a key ambition. Further, in such discussions perceived safety or feelings safety are coming to be recognized as significant for cyclists' mobilities. Such intentions are, in turn, echoed in the context of this paper's case study in that Plymouth City Council's (2011) transport plan specifically suggests that 'better journey experiences' are part of its vision. It is evident that planning for cycling has moved some way beyond the overly rationalized forms of transport planning often associated with the latter half of the $20^{\text {th }}$ century towards recognizing the importance of creating convivial environments in which various bodies move harmoniously.

That said, 'on the ground' transport infrastructure provision does seem, at times at least, to fall back on fairly well worn agendas and actions when it comes to cycling provisions. The challenge here becomes clear when trying to make the sorts of intentions mentioned above a reality in the actual outcomes of infrastructure and urban design. 
The Cycling and Walking Investment Strategy, for example, ultimately seeks to evaluate its success on the basis of various objectives measured by quantitative metrics around number of journeys made, injury rates, and age-specific participation. And again, in Plymouth's case targets are largely orientated towards doing something that can be clearly measured: increasing the connectivity of cycle paths and improved signage and route information. Less evident are considerations of how those spaces will actually come to be experienced by cyclists and other mobile bodies. Perhaps such felt experiences should come to be considered amongst the 'object-target' of planning and infrastructural development (Anderson 2014), and particularly in their evaluation, as much as manifest changes in the materiality of transport systems, quantifications of participation, and so on?

It is not, though, straightforward to design a specific atmosphere or feeling into a space (Bohme 2016). While great efforts are being made to engineer atmospheres in various forms of designed urban space, such interventions will not necessarily have a clear direct causality when it comes to the affective atmospheres and felt experiences they contribute towards. This is especially important to note when it comes to recent moves in transport planning in the UK towards 'shared space' designs, something that features strongly in the planning agendas mentioned above and emerged as contentious in this study. These are believed to encourage contextualized, negotiated, harmonious encounters between various mobile bodies and with that, convivial spaces. The findings here from Plymouth, though, have suggested that such interventions can serve to bring about uncongenial dispositions towards cyclists or seed more pointed, hostile atmospheres given the ambiguity over who belongs where, who has what rights and responsibilities, and more general issues over the expectation to encounter differently mobile bodies in the first place. Something as simple as a painted line can in fact bring about a range of unexpected and unplanned for affective experiences and hostile collective feelings that settle in different bodies in different ways. It is not simply the case of installing a specific type of (shared) infrastructure and assuming that its use will 
be 'figured out' and that it will bring about certain positive effects (and affects) for cyclists and pedestrians/other road users.

Exploring such issues further, one avenue of future research here would be to consider the diversity of mobile bodies and their varied registering of the atmospheres produced through mobile practices and infrastructures. It would be interesting to see how the experience of a similar space or atmosphere unfolds differently by a range of cyclists through, for example, focus group-based discussion. Further, the cyclists' comments made here on how they registered such various congenial and uncongenial atmospheres were clearly based on assumptions around the thoughts, feelings, and attitudes of these otherwise mobile bodies. Those other bodies may well have experienced those atmospheres differently, or found themselves within entirely different atmospheres (Anderson and Ash 2015). Considering the atmospheres produced in and through movement from a multi-modal perspective - one that takes into account the varied perspectives of other infrastructure users whose main mode of mobility is, for example, walking, or driving a car, or using a bus - would again develop the picture presented in terms of how transport infrastructure is experienced at an embodied, felt level. Finally, it is clear here that the experience of these infrastructure-influenced atmosphere emerged from more than just the relations between people and infrastructure. What it is like for cyclists to be, for example, amid the prevailing weatherworlds of these infrastructures and environments (Ingold 2007)? More elemental matters might also be considered, then, in terms of their significant to the production of conducive atmospheres for cyclists.

\section{References}

Ahmed S. 2010, "Happy Objects" In The Affect Theory Reader Eds Gregg M. and Seigworth G. J. (Duke University Press, London) pp. 29-51. 
Aldred R, 2010, “'On the outside': constructing cycling citizenship" Social and Cultural Geography 11(1) 35-52.

Aldred R, 2012, "Governing transport from welfare state to hollow state: The case of cycling in the UK" Transport Policy 23 95-102.

Aldred R, 2013, "Incompetent or Too Competent? Negotiating Everyday Cycling Identities in a Motor Dominated Society" Mobilities 8(2) 252-271.

Aldred R, Jungnickel K, 2014, "Why culture matters for transport policy: the case of cycling in the UK" Journal of Transport Geography 34 78-87.

Amin A, 2012, Land of Strangers (Polity Press, Cambridge).

Anderson B, 2005, "Practices of judgment and domestic geographies of affect" Social and Cultural Geography 6 645-659.

Anderson B, 2010, "Preemption, precaution, preparedness: Anticipatory action and future geographies" Progress in Human Geography 34 777-798.

Anderson B, 2014, Encountering Affect: Capacities, Apparatuses, Conditions (Ashgate, Abingdon).

Anderson B, Ash J, 2015, "Atmospheric Methods" In Nonrepresentational Methdologies: Re-envisioning Research Ed Vannini P. (Routledge, London) pp. 34-51.

Angelo $\mathrm{H}$, Hentschel C, 2015, "Interactions with infrastructure as windows into social worlds: A method for critical urban studies: Introduction" City 19 306-312. 
Bennett J, 2010, Vibrant Matter: A Political Ecology of Things (Duke University Press, London).

Bissell D, 2010 "Passenger mobilities: affective atmospheres and the sociality of public transport" Environment and Planning D: Society and Space 28 270289.

Bohme G, 2016, The Aesthetics of Atmosphere (Routledge, London).

Brown KM, 2012, "Sharing public space across difference: attunement and the contested burdens of choreographing encounter" Social and Cultural Geography 13 801-820.

Cupples J, Ridley E, 2008, “Towards a heterogeneous environmental responsibility: sustainability and cycling fundamentalism" Area 40 254-264.

Department for Transport, 2016, "Cycling and Walking Investment Strategy" Available at: https://www.gov.uk/government/consultations/draft-cycling-and-walkinginvestment-strategy .

Dourish P, Bell G, 2007, "The infrastructure of experience and the experience of infrastructure: meaning and structure in everyday encounters with space" Environment and Planning B: Planning and Design 34 414-430.

Graham S, 2001, "The city as sociotechnical process: Networked mobilities and urban social inequalities" City 3 339-349. 
Hamilton-Baillie B, 2008, "Shared Space: Reconciling People, Places and Traffic" Built Environment 34 161-181.

Horton D, 2007, "Fear of Cycling". In Cycling and Society Eds. Horton D, Rosen P, Cox P, (Ashgate, Aldershot) pp. 133-152.

Horton D, Rosen P, Cox P, 2007, "Introduction: Cycling and Society" In Cycling and Society Eds. Horton D, Rosen P, Cox P, (Ashgate, Aldershot) pp. 1-24.

Imrie R, 2012, "Auto-disabilities: the case of shared space environments" Environment and Planning A 44 2260-2277.

Ingold T. 2007, "Earth, sky, wind, and weather" Journal of the Royal Anthropological Institute (N.S.) S19-S38.

Jensen A, 2013, "Controlling mobility, performing borderwork: cycle mobility in Copenhagen and the multiplication of boundaries" Journal of Transport Geography 30 220-226.

Jones P, 2005, "Performing the city: a body and a bicycle take on Birmingham, UK" Social and Cultural Geography 6(6) 813-830.

Jones P, 2012, "Sensory indiscipline and affect: a study of commuter cycling" Social \& Cultural Geography 13(6) 645-658.

Jones T, 2012, "Getting the British back on bicycles - The effects of urban traffic-free paths on everyday cycling" Transport Policy 20 138-149. 
McCormack DP, 2008, "Engineering affective atmospheres on the moving geographies of the 1897 Andree expedition" Cultural Geographies 15 413-430.

McCormack DP, 2014, "Atmospheric things and circumstantial excursions" Cultural Geographies 21(4) 605-625.

Menghini G, Carrasco N, Schussler N, Axhausen KW, 2010 "Route choice of cyclists in Zurich" Transportation Research Part A 44 754-765.

Merriman P, 2014, "Rethinking mobile methods" Mobilities 9 167-187.

Merriman P, 2016, "Mobility Infrastructures: Modern Visions, Affective Environments and the Problem of Car Parking" Mobilities 11 83-98.

Nancy J-L, 1997, The Sense of the World (University of Minnesota Press, London).

Nixon DV, 2012, "A sense of momentum: mobility practices and dis/embodied landscapes of energy use" Environment and Planning A 44 1661-1678.

Parkin J, Ryley T, Jones T, 2007 "Barriers to Cycling: An Exploration of Quantitative Approaches" In Cycling and Society Eds. Horton D, Rosen P, Cox P, (Ashgate, Aldershot) pp. 67-82.

Parkin J, Wardman M, Page M, 2007, "Models of perceived cycling risk and route acceptability" Accident Analysis and Prevention 39 364-371.

Plymouth City Council, 2011, "Local Transport Plan: 2011-2026" Available at http://www.plymouth.gov.uk/ltp. 
Plymouth City Development Company, undated, "Commuting" Available at: http://www.plymouth.gov.uk/cdc commuting.pdf

Pucher J, Dill J, Handy S, 2010, "Infrastructure, programs, a policies to increase bicycling: An international review" Preventative Medicine 50 S106-S125.

Shaw J, Hesse M, 2010, "Transport, geography and mobilities" Transactions of the Institute of British Geographers 35(3) 305-312.

Simpson P, 2014, "Video" In The Routledge Handbook of Mobilities Eds. Adey P, Bissell D, Hannam K, Merriman P, Sheller M, (Routledge, London) pp. 542-552.

Skinner D, Rosen P, 2007, "Hell is Other Cyclists: Rethinking Transport and Identity" In Cycling and Society Eds. Horton D, Rosen P, Cox P, (Ashgate, Aldershot) pp. 83-96.

Spinney J, 2006, "A place of sense: a kinaesthetic ethnography of cyclists on Mont Ventoux" Environment and Planning D: Society and Space 24 709-732.

Spinney J, 2008, "Cycling between the traffic: Mobility, identity and space" Urban Design 108 28-30.

Spinney J, 2009, "Cycling the City: Movement, Meaning and Method" Geography Compass 3/2 817-835.

Spinney J, 2011, "A chance to catch a breath: Using mobile video ethnography in cycling research" Mobilities 6 161-182. 
Stewart K, 2011 "Atmospheric attunements" Environment and Planning D: Society and Space 29 445-453.

Tonkiss F, 2015 "Afterword: Economies of infrastructure" City 19 384-391.

van Duppen J, Spierings B, 2013, "Retracing trajectories: the embodied experience of cycling, urban sensescapes and the commute between 'neighbourhood' and 'city' in Utrecht, NL" Journal of Transport Geography 30 234-243.

Vreugdenhil R, Williams S, 2013, "White line fever: a sociotechnical on the contested implimentation of an urban bike lane network" Area 45 283-291. 